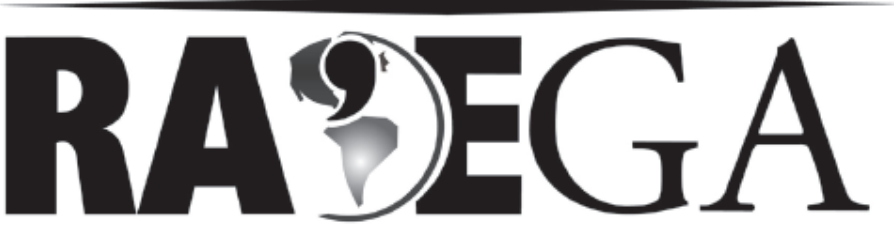

O ESPAÇO GEOGRÁFICO EM ANÁLISE

\title{
A CENTRALIDADE DE LONDRINA, MARINGÁ, CASCAVEL, PONTA GROSSA E GUARAPUAVA NA REDE URBANA DO PARANÁ
}

\section{THE CENTRALITY OF LONDRINA, MARINGÁ, CASCAVEL, PONTA GROSSA AND GUARAPUAVA IN THE URBAN NETWORKS OF PARANÁ}

\author{
Sandra Cristina Ferreira ${ }^{1}$
}

\section{RESUMO}

O Estado do Paraná, embora com ocupação territorial que remonta ao século XVI, teve sua rede urbana organizada e dinamizada a partir da década de 1970, quando um conjunto de transformações político-ecomômicas e sociais promoveram transformações que resultaram na urbanização, industrialização, aumento do número de cidades e de habitantes na área urbana. Desde então, algumas urbes segundo a oferta de bens e serviços, a diversificação de atividades produtivas e a concentração de infraestrutura em quantidade e qualidade superior à outras, destacam-se na hierarquia urbana paranaense. Apresentamos nesse artigo, a evolução da centralidade de Londrina, Maringá, Cascavel, Ponta Grossa e Guarapuava como importantes cidades na rede urbana do Paraná com semelhanças e diferenças que resultam na posição hierárquica que ocupam na rede. Objetivamos demonstrar a densidade de população, de cidades e de fluxos em cada região de influência, ressaltando processos políticos e econômicos que contribuíram para a formação, desenvolvimento e expansão das redes urbanas regionais. A posição das cidades na rede urbana paranaense verificada pela sequencia de estudos do IBGE de 1966, 1978, 1993 e 2007, expressa a dinâmica

\footnotetext{
${ }^{1}$ Geógrafa. Professora Doutora da Universidade Estadual do Centro Oeste do Paraná/UNICENTRO scferreira@unicentro.br / sheideche@hotmail.com
} 
socioeconômica das urbes e a capacidade de intermediação de cada uma em seus contextos regionais e em âmbito estadual.

Palavras chave: Rede urbana, Paraná, centralidade, cidades, região de influência.

\begin{abstract}
The state of Paraná, albeit with a territorial occupation dating back to sixteenth century, had its urban network organized and streamlined from the 1970s, when a series of social political-economic transformations promoted changes that resulted in urbanization, industrialization, an increase in the number of cities and inhabitants in the urban areas. Since, some cities stand out in the urban hierarchy of Paraná, according to the goods and services offers, the diversification of productive activities and the concentration of infrastructure in quantity and quality superior to others. In this article it is presented the centrality evolution of Londrina, Maringá, Cascavel, Ponta Grossa and Guarapuava as important cities of the urban network of Paraná, with the similarities and differences that result in the hierarchy position that each of these cities occupy in the network. What we expect is to demonstrate with the population density, cities and flows in each region of influence, the differences between these cities, highlighting the political and economic processes that contributed to the formation, development and expansion of the regional urban networks. The position of cities in the urban network in Paraná is verified by the studies sequence of IBGE/REGIC of 1986, 1978, 1993 and 2007 that express the socioeconomic dynamic of these cities and the capacity of intermediation of each one in their regional contexts and statewide.
\end{abstract}

Keywords: Urban network, Paraná, centrality, cities, region of influence.

\title{
1. Introdução
}

O nível de centralidade que uma cidade apresenta na rede urbana demonstra sua importância quanto as interações espaciais que estabelece com outros centros urbanos e denota a relevância funcional que no estudo realizado pelo IBGE (Instituto Brasileiro de Geografia e Estatística) denominado REGIC (Região de Influência de Cidades), fundamenta-se pela oferta segundo a variedade, quantidade e qualidade de bens e serviços oferecido a uma demanda local e a habitantes de outras urbes que se deslocam para usufruí-los . 
Tomando por referência os estudos realizados pelo IBGE/REGIC em 1966, 1978, 1993 e em 2007, e o estudo denominado "Comentários sobre os resultados do REGIC 2007", produzido e publicado pelo IPARDES (Instituto Paranaense de Desenvolvimento Econômico e Social) em 2009, refletimos e apresentamos as principais alterações na posição de Londrina, Maringá, Cascavel, Ponta Grossa e Guarapuava na hierarquia urbana do Paraná no decorrer dos mencionados períodos. Objetivamos com isso, demonstrar as diferenças em densidade de população, quantidade de cidades e intensidade de fluxos em cada região de influência e ressaltar alguns processos políticos e econômicos que contribuíram para a formação, desenvolvimento e expansão das redes urbanas regionais.

As informações apresentadas em mapas e tabelas evidenciam a quantidade de núcleos urbanos sob a centralidade de cada urbe, o tamanho demográfico desses núcleos e demonstram os fluxos que articulam as cidades. Tais dados revelam também, as áreas em que se encontram maior quantidade de cidades com mais de 50 e mais de 100 mil habitantes expressando uma geografia urbana constituída por cidades de diferentes tamanhos e dinâmica resultante de processos sociais, políticos e econômicos desiguais, tanto no espaço, quanto no tempo culminando na participação diferenciada de cada urbe na rede urbana.

\section{As redes urbanas regionais na estruturação da rede urbana do Paraná}

A participação das cidades na rede urbana com o estabelecimento de funções consiste num processo contínuo e mutável de produção da própria rede que exibe características associadas aos diferentes momentos de sua formação. As redes urbanas regionais como as abordadas nesse texto, apresentam particularidades inerentes à sua formação socioespacial, mas, exibem também características de redes urbanas mais complexas a que podem estar associadas.

Tanto os processos desencadeados em escala local/regional, quanto os produzidos em outras escalas espaciais mais amplas repercutem na formação e desenvolvimento das cidades e na definição de funções na rede. Os estudos do 
IBGE/REGIC tiveram início em meados da década de 1960, quando no estado do Paraná as políticas de desenvolvimento territorial priorizavam reproduzir o modelo de produção pautado na indústria, na modernização da agricultura e na criação de cidades dotadas de infraestrutura para atuarem como centros de disseminação de desenvolvimento e atendimento da população residente em sua proximidade. Tais objetivos incluídos no I Plano Nacional de Desenvolvimento (1972-1974), tinham como âncora para o setor urbano e industrial, a criação das cidades de porte médio por meio do PNCCPM - Programa Nacional de Apoio às Capitais e Cidades de Porte Médio e a implantação e expansão de redes de energia, transportes, telefonia entre outras que pudessem estimular e oportunizar a urbanização e a industrialização. No Paraná, tal plano foi seguido de perto e as medidas políticoeconômicas adotadas associadas às características empreendedoras das elites locais contribuíram para mudanças nos papéis das cidades e a configuração da rede urbana.

Na Figura 1 encontra-se a distribuição das principais hierarquias no estado com a localização das cidades pesquisadas segundo o ano em que foi realizada a pesquisa pelo IBGE/REGIC. Em 1966, na sequência hierárquica da rede urbana do Paraná, apareciam Londrina e Ponta Grossa, como Centros Regionais A, e Maringá como Centros Regionais $B$, destacando-se o importante papel desempenhado por Ponta Grossa nessa época, bastante modificado, cada qual por suas especificidades, comparativamente a 2007, que classifica Ponta Grossa como Capital Regional C, tendo em posições superiores Londrina, Maringá e Cascavel (Capitais Regionais B) (IBGE/REGIC, 2008).

Entre essas categorias superiores, cabe 0 destaque a Cascavel, que em 1966 classificava-se como Centro Sub-regional A, passando em 1978 à Capital Regional, posição na qual se mantém na pesquisa mais recente, como Capital Regional B. Cascavel foi uma das cidades eleitas para constituir um pólo de crescimento pelo PNCCPM do governo federal, assim como Londrina, Maringá, Ponta Grossa, Paranaguá e Guarapuava. Ressaltamos que a mesma cidade foi considerada no Plano de Desenvolvimento Urbano do governo paranaense em 
1972, assim como Londrina, Maringá e Ponta Grossa recebendo incentivo como as demais cidades citadas, para consolidar-se como um importante núcleo urbano para a região Oeste do estado.

A pesquisa do IBGE/REGIC em 1993 adotou um novo padrão classificatório, mas que manteve semelhanças com as categorias anteriormente definidas. Revelou um reequilíbrio na rede de cidades, seja por detalhes metodológicos seja pelo próprio rearranjo sofrido e consolidado pelo conjunto de centralidades. A classificação resultante se expressa em níveis de centralidade, e, no nível máximo, enquadra-se apenas Curitiba. No nível muito forte enquadram-se Londrina e Maringá, havendo um descenso de Londrina, ofuscada tanto pelo crescente poder concentrador de Curitiba quanto pela ascensão de Maringá, que se posiciona entre os principais centros do Paraná. Ressalte-se que as duas Capitais Regionais A, identificadas em 1966, diziam respeito a Londrina e Ponta Grossa, e que esta última deve seu declínio na hierarquia pela proximidade com Curitiba.

A pesquisa de 1978 introduziu a categoria de Centro Sub-metropolitano, como segunda posição na hierarquia de centros do Brasil, que não se manteve nas pesquisas posteriores. Londrina ocupou essa posição num momento em que a economia do Estado ainda não estava tão concentrada no entorno de Curitiba, e ainda vivenciava o apogeu econômico do Norte Central favorecido, sobretudo, pela produção e comercialização do café. O declínio de Londrina na escala estadual da rede urbana associa-se à consolidação da CIC (Cidade Industrial de Curitiba), criada em 1973 e a implantação na mesma década do polo Petroquímico em Araucária o que impulsionou a concentração da renda, a diversificação produtiva e as atividades de comércio e serviços.

A concentração espacial dessas atividades em Curitiba e Londrina distanciou as duas cidades dos demais centros paranaenses (IPARDES, 2009). Os resultados da pesquisa de 1978 registram também, o período em que a modernização do campo provocou intenso êxodo do rural para o urbano, reforçando um grande conjunto de centros regionais no interior do Estado, sendo 
identificados quatro Centros Regionais na pesquisa de 1966, passando a oito, na categoria compatível da pesquisa de 1978 (Figura 1).

Estavam, assim, definidos em 1993 dois conjuntos importantes de centralidades no Estado: o metropolitano, considerando Ponta Grossa em seu entorno mais distante, com um centro de nível máximo e outro de nível forte; e o do Norte Central, com dois centros de nível muito forte. Esses conjuntos se mantêm como os mais expressivos do Estado na pesquisa de 2007. Estudos do IPARDES $(2005$; 2006) apontam para uma aproximação espacial de centralidades no Norte Central paranaense, com as ACPs (Áreas de Concentração Populacional) de Londrina e Maringá polarizando um conjunto urbano que ainda conta com Apucarana, classificado como Centro Sub-regional A, e para uma organização mais complexa, unindo, numa mesma espacialidade, as ACPs de Curitiba, Paranaguá e Ponta Grossa, com seus respectivos municípios aglomerados. 
Figura 1: Cidades na hierarquia urbana do Paraná - 1966, 1978, 1993 e 2007

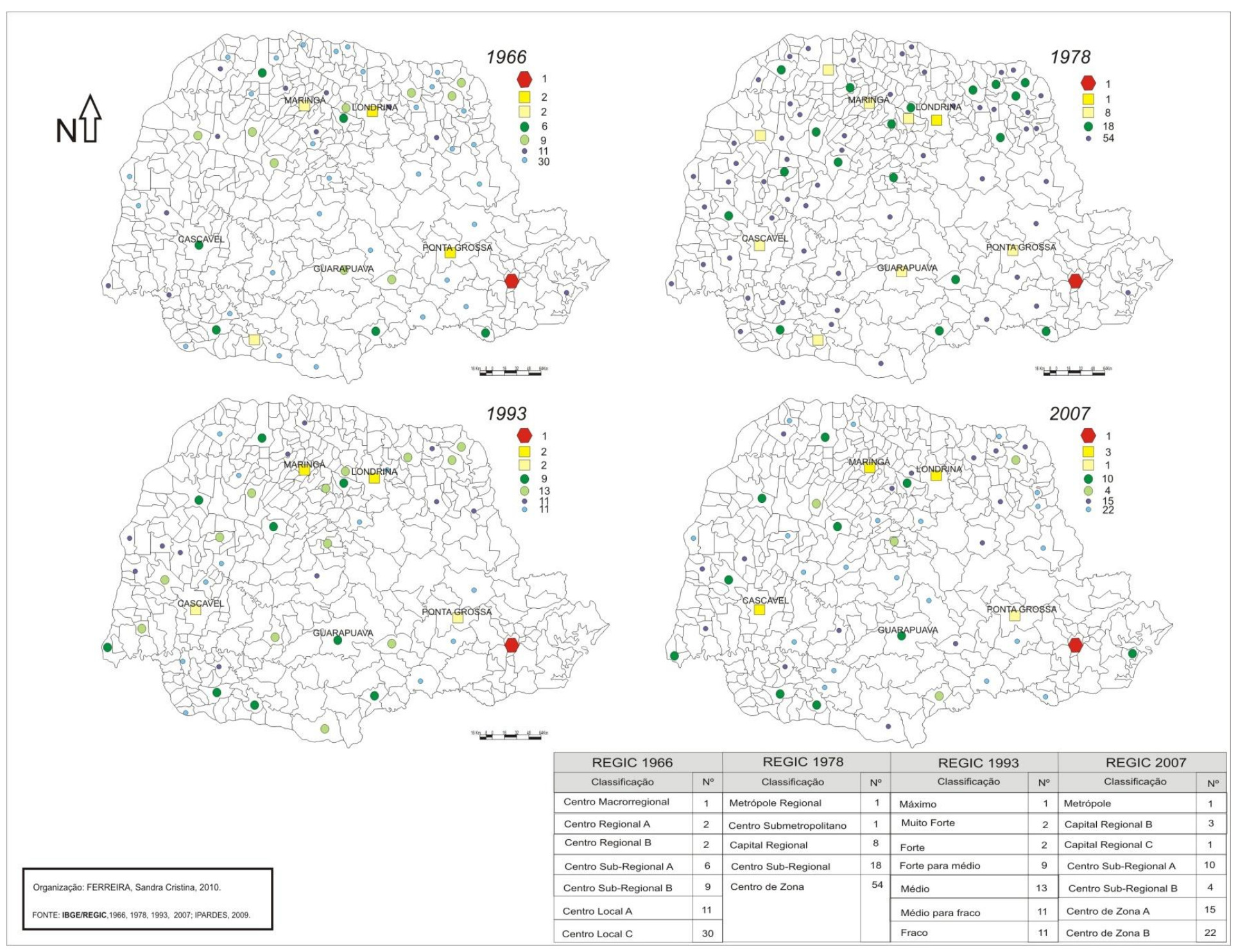


A pesquisa de 2007 ainda revela um novo elo importante da rede, que se fortalece no Oeste paranaense, com a ascensão de Cascavel à categoria de Capital Regional B. Alguns estudos (IPARDES, 2008; REOLOM, 2007) apontam inclusive a configuração de uma aglomeração bipolarizada por Cascavel e Toledo, este classificado como Centro Subregional $A$, além da conformação de um eixo, a partir dessa aglomeração, articulando um conjunto de pequenas centralidades, sendo Foz do Iguaçu, também classificado como Centro Sub-regional A (IBGE/REGIC, 2008).

Desse conjunto de cidades resultou, em 2007, a configuração de uma rede urbana com poucas alterações quanto aos papéis das cidades na rede que reforça algumas centralidades como Londrina, Maringá, Cascavel, Ponta Grossa estendendo até Curitiba conforme demonstra a Figura 2, com a distribuição das cidades e respectivas regiões de influência, permitindo perceber as áreas de maior e menor concentração de cidades e a formação de fluxos. Nas hierarquias inferiores dessa rede, como uma tendência percebida pelas informações ressaltadas na sequência de estudos do IBGE, ocorreu um maior número de ascensões, principalmente entre centros que atingiram 50 e 100 mil habitantes nesse período ou que declinaram em população e dinâmica. Tal informação reforça que a área com menos fluxos e articulações à rede estadual compreende a região Central do Paraná, como detalharemos mais adiante nesse texto, mas, que a leitura da Figura 2, nos antecipa.

A região Centro Sul configura um espaço com cidades mais dispersas e menos articuladas, principalmente de Guarapuava em direção às cidades de Ivaiporã, União da Vitória, Francisco Beltrão, Pato Branco e Cascavel ao mesmo tempo em que demonstra a inexistência de concentração de cidades com população entre 50 e 100 mil habitantes nesse recorte, prevalecendo as pequenas cidades com população inferior a 50 mil habitantes e predominância de atividades vinculadas ao campo. A concentração de cidades pequenas com reduzida oferta de bens e serviços associada às condições sociais críticas da população (IPARDES, 2005, 2006), resulta em baixo dinamismo econômico e menor intensidade de fluxos entre as urbes 


\section{Figura 2: Classificação e região de influência das cidades no Paraná-2007}

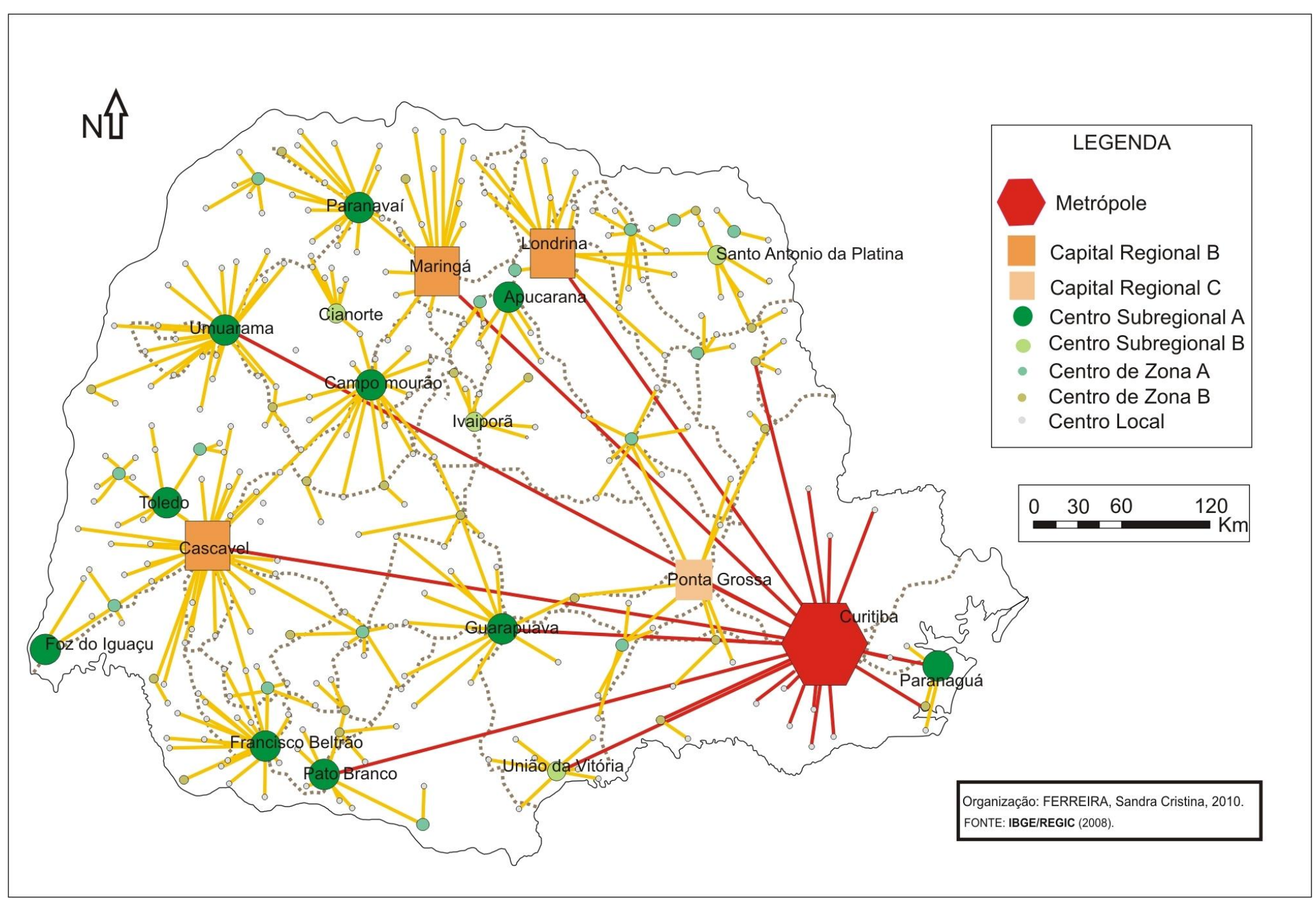


A partir dessa compreensão geral da rede urbana paranaense por meio da distribuição espacial das cidades segundo a hierarquia na rede, entendemos que a aproximação com a escala regional detalhando as áreas de influência de Londrina, Maringá, Cascavel, Ponta Grossae Guarapuava evidencia a relação das cidades e respectiva população urbana que estão sob a influência direta das cinco urbes supracitadas. As figuras que representam cada região de influência, demonstram a origem e a direção dos fluxos que se formam em cada recorte espacial permitindo a compreensão do alcance (máximo, médio ou mínimo) das centralidades abordadas. Por serem os Centros Locais considerados pelo IBGE/REGIC (2008) com população em média de 10 mil habitantes os apresentamos nas tabelas agrupados segundo esse patamar populacional.

\section{Região de influência de Londrina, Maringá, Cascavel, Ponta Grossa e Guarapuava}

A partir de 1970, em virtude das mudanças estruturais referentes à economia, a intensa dispensa de mão-de-obra rural e à expansão da fronteira agrícola para o Sudoeste encaminha-se a definição da ocupação territorial no Estado. Deflagra-se a modernização e diversificação agrícola, o movimento campo-cidade, a concentração populacional em alguns centros urbanos, a urbanização e a industrialização. É, sobretudo a partir da década de 1970, que podemos pensar na organização do que seria o Paraná moderno sob as determinações políticas e econômicas que afetaram de maneira diferenciada seu espaço e sociedade criando as condições gerais para a estruturação da rede urbana.

Os desdobramentos referentes a concentração populacional, a industrialização, modernização agrícola e urbanização, no que tange à constituição da rede de cidades, resultaram, além da capital com 1.851.215 habitantes (IBGE, 2007), em 370 cidades com população até 50 mil habitantes, quinze cidades com população entre 50 e 100 mil habitantes e doze cidades com população entre 100 e 500 mil habitantes. Observamos que o censo de 2010 aponta Londrina com mais de 500 mil habitantes, mas que para essa análise nos pautamos nos estudos do IBGE com dados de 2007.

As regiões Norte, Oeste e a de Curitiba e Região Metropolitana estendendo até Ponta Grossa concentram maior número de cidades com mais de 50 e mais de 100 mil habitantes constituindo importantes pontos para articulação em rede. Desde a década de 1980, quando o Paraná passava a apresentar maior população urbana que rural, as cidades entre 50 e 500 mil habitantes exercem papel de dinamização apresentando níveis de desenvolvimento 
RA'E GA 23 (2011), p. 06-31

www.geografia.ufpr.br/raega/

Curitiba, Departamento de Geografia - UFPR

ISSN: 2177-2738

urbano, econômico e populacional diferenciado, demarcando geograficamente a rede urbana do Estado com regiões de influência mais amplas. A quantidade e o porte demográfico das cidades pertencentes às respectivas regiões de influência auxiliam na compreensão dessas dinâmicas tendo em vista que, nesse caso, as áreas mais populosas convergem com as mais dinâmicas socioeconomicamente, apesar, dessa característica, ressaltamos que tais áreas tendem também concentrar volumosos problemas socioambientais (MOURA, 2004).

\subsection{Região de influência de Londrina e Maringá}

As cidades de Londrina e Maringá formam juntas um adensamento de interações que se estendem desde os centros com proximidade imediata a outros mais distantes. Sob a influência direta de Londrina encontram-se as cidades dispostas na Tabela 1, com suas respectivas classificações na hierarquia urbana e número de habitantes na área urbana.

\begin{tabular}{|c|c|c|}
\hline Cidades & Classificação & $\begin{array}{c}\text { População } \\
\text { Urbana }\end{array}$ \\
\hline Apucarana & Centro Sub-regional A & 108.498 \\
\hline Ivaiporã & Centro Sub-regional A & 26.397 \\
\hline Santo Antônio da Platina & Centro Sub-regional A & 34.194 \\
\hline Arapongas & Centro de Zona A & 93.717 \\
\hline Bandeirantes & Centro de Zona A & 27.785 \\
\hline Cornélio Procópio & Centro de Zona A & 43.865 \\
\hline Ibaiti & Centro de Zona A & 21.966 \\
\hline Jacarezinho & Centro de Zona $\mathrm{A}$ & 34.667 \\
\hline Jandaia do Sul & Centro de Zona A & 17.449 \\
\hline Andirá & Centro de Zona B & 19.847 \\
\hline Faxinal & Centro de Zona B & 11.318 \\
\hline Siqueira Campos & Centro de Zona B & 12.135 \\
\hline $\begin{array}{l}\text { Alvorada do Sul, Assaí, Bela Vista do } \\
\text { Paraíso, Cafeara, Centenário do Sul, } \\
\text { Curiúva, Figueira, Florestópolis, Guaraci, } \\
\text { Jaboti, Jaguapitã, Jardim Alegre, } \\
\text { Jataizinho, Lupionópolis, Mirasselva } \\
\text { Pinhalão, Porecatu, Prado Ferreira, } \\
\text { Primeiro de Maio, Ribeirão do Pinhal, } \\
\text { Santa Cecília do Pavão, São Jerônimo } \\
\text { da Serra, São João do Ivaí, Sapopema, } \\
\text { Sertanópolis, Tamarana. }\end{array}$ & Centros Locais & $\begin{array}{c}\text { Cidades com } 10 \\
\text { mil habitantes em } \\
\text { média }\end{array}$ \\
\hline
\end{tabular}

Fonte: IBGE/REGIC(2008, p.67-68), IBGE (2007) Contagem da População, 2007.

Org.: FERREIRA, S. C. 2010. 
Sob a influência direta de Londrina, se localizam três Centros Sub-regionais A, Santo Antonio da Platina, Ivaiporã e Apucarana com mais de 100 mil habitantes. Entre os seis Centros de Zona A, as cidades mais populosas são Arapongas com 93. 717 mil habitantes e Cornélio Procópio com 43.865 mil habitantes. Os Centros de Zona B, são três cidades com menos de 20 mil habitantes e mais 27 Centros Locais. Estas cidades se articulam a Londrina e estabelecem relações com outros centros urbanos de sua hinterlandia. $\mathrm{Na}$ região de influência de Maringá (Tabela 2), se encontram menor número de cidades que Londrina e com menor número de habitantes.

Os Centros Sub-regionais A, correspondem às cidades de Campo Mourão com 77.796 mil habitantes e Paranavaí com 77.463 mil habitantes na área urbana respectivamente. Cianorte como Centro Sub-regional B com 57.321 mil habitantes, um Centro de Zona A e três Centros de Zona B com menos de 30 mil habitantes e 29 Centros Locais. Juntas, Londrina e Maringá formam uma densa rede de cidades articuladas entre si e à centros maiores. No Norte paranaense, "as redes de Londrina e Maringá passaram a integrar a rede de Curitiba e não mais somente a rede de São Paulo", como prevalecia desde o estudo de 1966 (IBGE/REGIC, 2008, p.18), ampliando, assim, o alcance da rede de Curitiba.

\begin{tabular}{|c|c|c|}
\hline Cidades & Classificação & População Urbana \\
\hline Campo Mourão & Centro Sub-regional A & 77.796 \\
\hline Paranavaí & Centro Sub-regional A & 73.463 \\
\hline Cianorte & Centro Sub-regional B & 57.321 \\
\hline Loanda & Centro de Zona A & 17.234 \\
\hline Campina da Lagoa & Centro de Zona B & 12.752 \\
\hline Goioerê & Centro de Zona B & 24.991 \\
\hline Nova Londrina & Centro de Zona B & 10.963 \\
\hline $\begin{array}{l}\text { Ângulo, Astorga, Atalaia, Colorado, } \\
\text { Cruzeiro do Sul, Doutor Camargo, } \\
\text { Engenheiro Beltrão, Floraí, Flórida, } \\
\text { lguaraçu, Itaguajé, Itambé, Jardim } \\
\text { Olinda, Lobato, Mandaguaçu, Munhoz } \\
\text { de Melo, N.. Senhora das Graças, Nova } \\
\text { Esperança, Ourizona, Paranapoema, } \\
\text { Paranacity, Roncador, Presidente } \\
\text { Castelo Branco, Santa Fé, Santa Inês, } \\
\text { Santo Inácio, São Jorge do Ivaí, Uniflor. }\end{array}$ & Centros Locais & $\begin{array}{c}\text { Cidades com até } 10 \text { mil } \\
\text { habitantes }\end{array}$ \\
\hline
\end{tabular}


O conjunto de atividades econômicas realizadas na região Norte do Paraná e as interações entre os demais municípios constituem um espaço com matriz produtiva que se assemelha a Curitiba e Região Metropolitana (IPARDES, 2008). Diferenciam-se por manter a participação no total na produção do estado por meio da agropecuária e o setor industrial, enquanto Curitiba e RM destacam a indústria e o terciário. Como as principais centralidades da região Norte paranaense, Londrina contribuiu em 2008 segundo a SEFA/PR com $R \$$ 4.096.279.347 de VAF/Total para o Estado e Maringá com R\$ 3.645.288.146. A Figura 3, expõe a geografia dos fluxos entre Londrina, Maringá com suas respectivas regiões de influência. 


\section{Figura 3: Região de Influência de Londrina e Maringá - 2007}

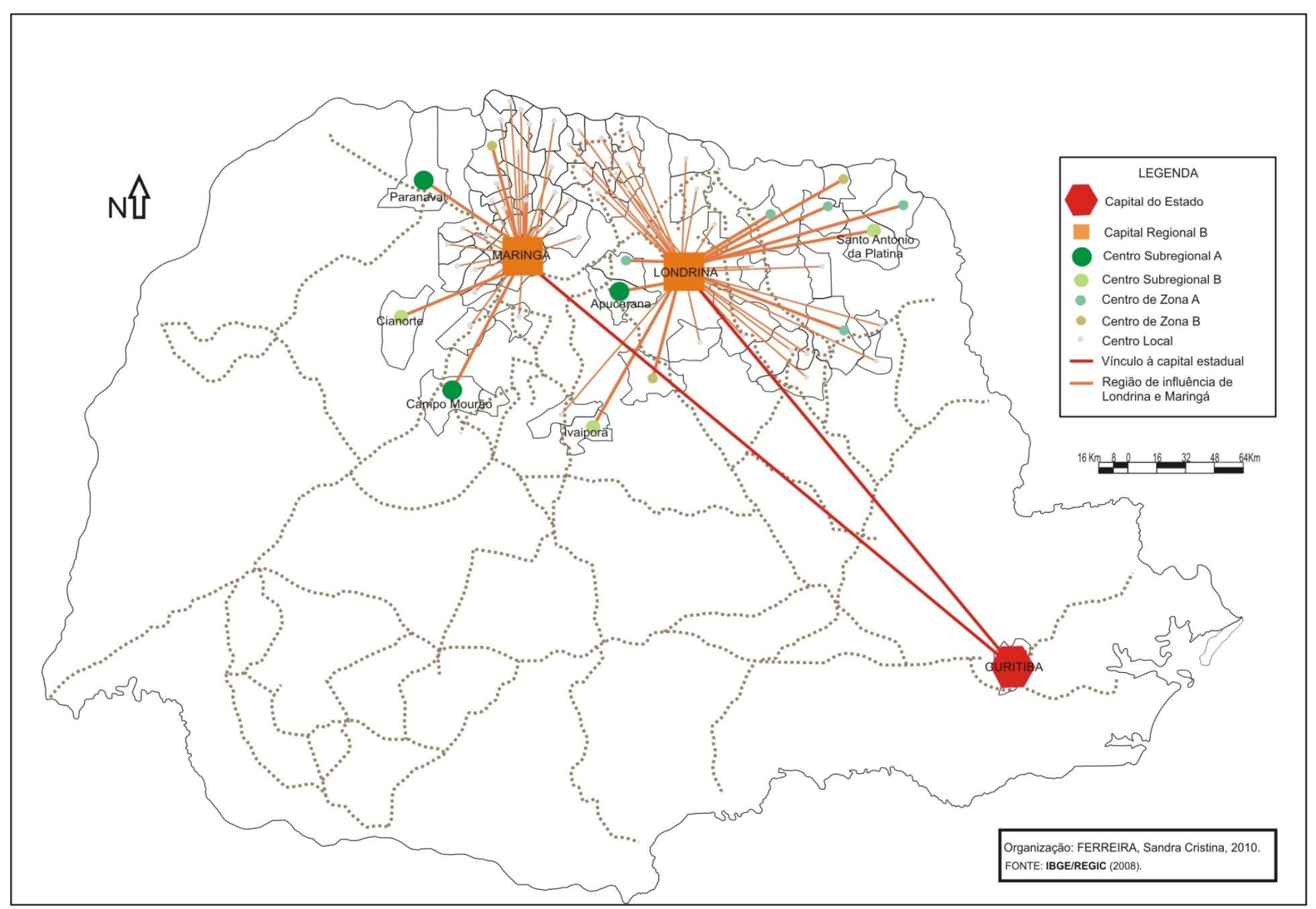




\subsection{Região de influência de Cascavel}

As cidades que estão sob a região de influência de Cascavel (Tabela 3 e Figura 4) compreendem a Foz do Iguaçu como Centro Sub-regional A, com 325.137 mil habitantes com quem estabelece relação de complementaridade numa situação particular, pois embora Foz do Iguaçu apresente esse volume populacional e forte comércio com relação internacional, têm suas atividades mais intensas voltadas para as relações de fronteira e em torno da Usina de Itaipu, não estendendo centralidade significativa sobre os municípios da região que são polarizados por Cascavel. Os outros dois Centros Sub-regionais são Francisco Beltrão e Toledo com 60.798 e 98.606 mil habitantes respectivamente. Além destas cidades, estão cinco Centros de Zona A, com população entre 24 e 35 mil habitantes, um Centro de Zona $B$ e vinte e oito Centros Locais.

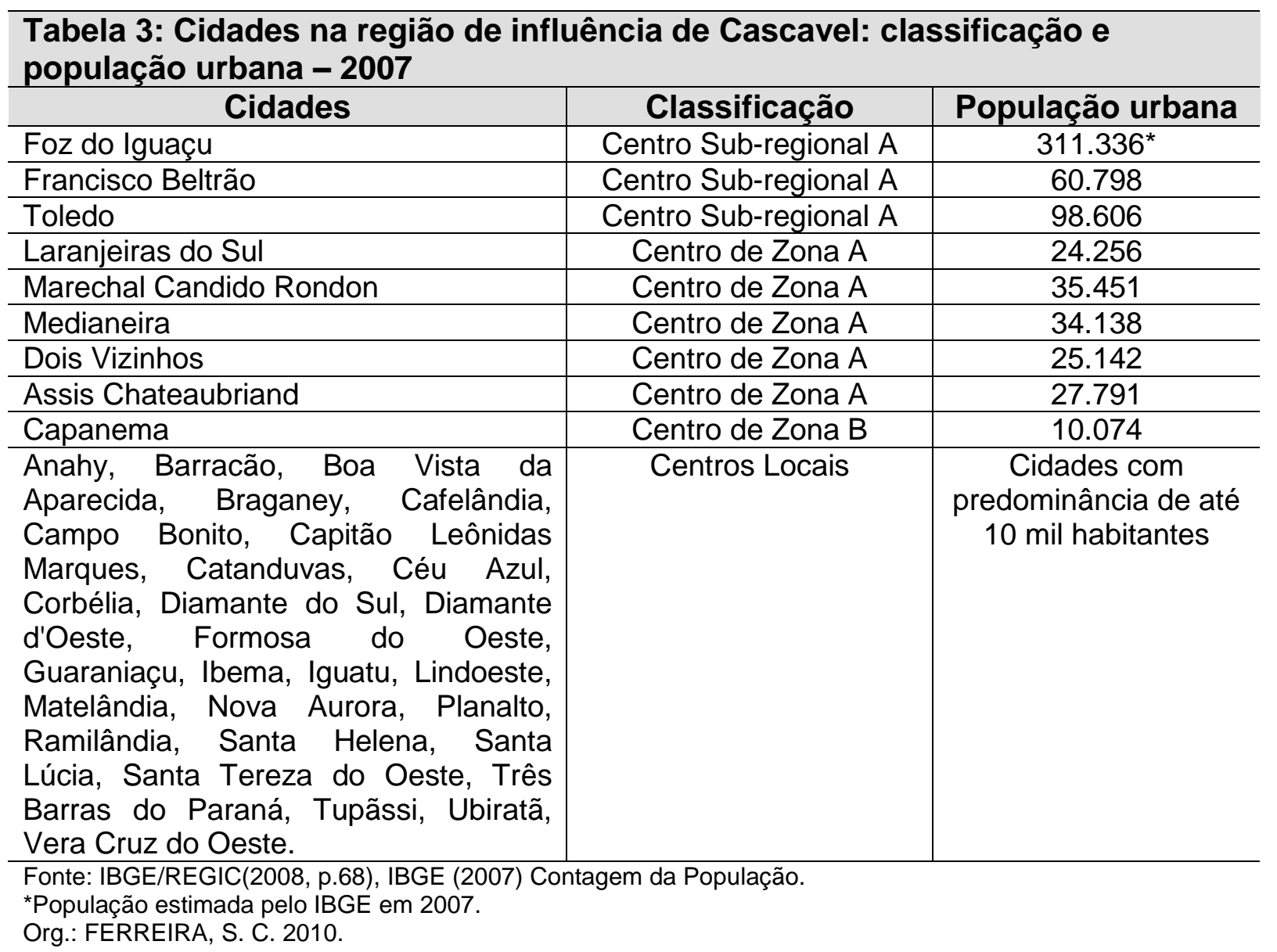




\section{Figura 4: Região de Influência de Cascavel - 2007}

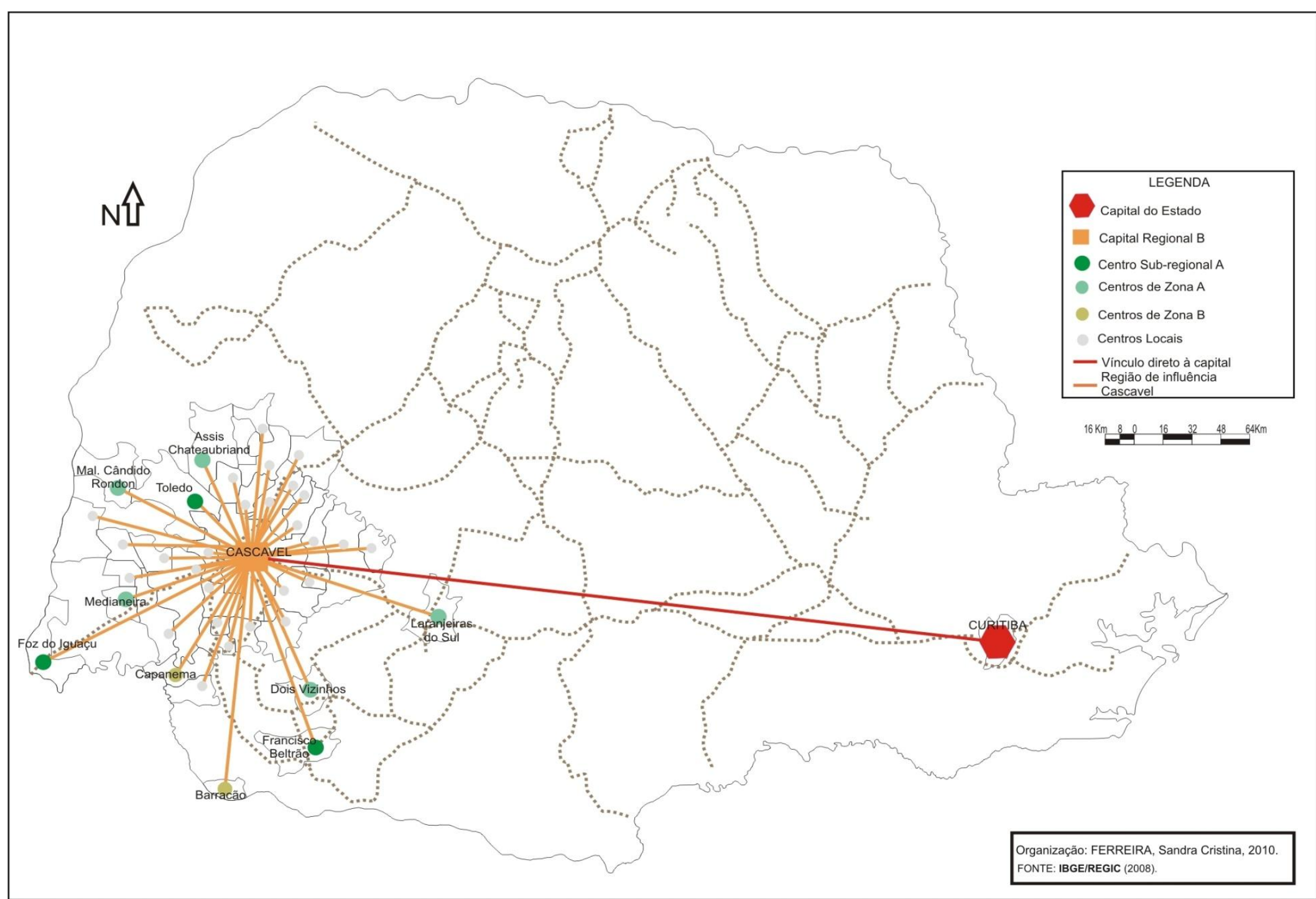


Localizada na região Oeste do Paraná, Cascavel (Capital Regional B), apresenta vetores de dinamismo para Foz do Iguaçu e Toledo. Articula-se à capital do estado do Paraná e a outros centros como Francisco Beltrão, Marechal Candido Rondon e Pato Branco no Sudoeste. A inserção de Cascavel à DST (Divisão Social do Trabalho), dá-se a partir de um número maior de atividades ligadas fundamentalmente à produção agroindustrial e de serviços.

A posição próxima a Foz do Iguaçu estimula a atividade turística, comércio e relações internacionais, contribuindo para a geração de riquezas e, estreita vínculos com países do MERCOSUL (Mercado Comum do Sul). Cascavel desempenha o complexo papel de polarizar uma aglomeração de fronteira internacional (IPARDES, 2008) e, contribuiu com $R \$$ 2.849.669.946 do VAF/Total do município em 2008 (SEFA/PR, 2008).

\subsection{Região de influência de Ponta Grossa}

Ponta Grossa tem seu dinamismo intensificado pelas atividades industriais voltadas para os segmentos metalquímicos, químicos, plásticos e de alimentos agregando também um diversificado setor de comércio e serviços e destaca-se quanto a localização por constituir-se num importante entroncamento rodoferroviário. Apresenta sob sua região direta de influência as cidades apresentadas na Tabela 4 abaixo.

\begin{tabular}{|c|c|c|}
\hline Cidades & Classificação & $\begin{array}{c}\text { População } \\
\text { Urbana }\end{array}$ \\
\hline Irati & Centro de Zona A & 42.196 \\
\hline Telêmaco Borba & Centro de Zona A & 63.544 \\
\hline Jaguaraíva & Centro de Zona B & 27.633 \\
\hline Palmeira & Centro de Zona B & 18.480 \\
\hline Prudentópolis* & Centro de Zona B & 21.661 \\
\hline $\begin{array}{l}\text { Carambeí, Castro (PR), Ipiranga (PR), } \\
\text { Ivaí (PR), Piraí do Sul (PR), Porto } \\
\text { Amazonas. }\end{array}$ & Centros Locais & $\begin{array}{l}\text { Cidades com até } \\
10 \text { mil habitantes }\end{array}$ \\
\hline Castro $^{* *}$ & Centro Local & 47.294 \\
\hline \multicolumn{3}{|c|}{$\begin{array}{l}\text { “Encontra-se também sob a área influência de Guarapuava. } \\
\text { Fonte: IBGE/REGIC(2008, p.68), IBGE (2007) Contagem da População. } \\
\text { Org.: FERREIRA, S. C. 2010. } \\
{ }^{* *} \text { f fato de o município de Castro ter sido classificado como Centro Local está ligado a sua } \\
\text { proximidade em relação a Capital Regional C de Ponta Grossa, a qual atrai diretamente os fluxos dos } \\
\text { centros menores segundo IBGE, } 2008 \text {. }\end{array}$} \\
\hline
\end{tabular}


Ponta Grossa (Capital Regional C), exerce centralidade sob dois Centros de Zona A, Irati com 42.196 mil habitantes e Telêmaco Borba, com 63.544 mil habitantes, ambas com produtividade expressiva vinculada à madeira. Mantêm ainda sob sua influência direta três Centros de Zona B, com população entre 18 e 30 mil habitantes e seis Centros Locais, entre eles Castro com população urbana de 47.294 mil habitantes (Figura 5). Cabe aqui um esclarecimento metodológico, pois Castro, embora com quase 50 mil habitantes na área urbana, tem sua centralidade reduzida pela influência de Ponta Grossa e assim, desempenha papéis equivalentes aos demais Centros Locais e, por isso, encontra-se agrupado junto a essa categoria de cidades, segundo os critérios adotados pelo IBGE/REGIC(2008).

Na região de influência de Ponta Grossa, não se localiza nenhum Centro Sub-regional, ao contrário do que acontece em Londrina Maringá e Cascavel. Sob a influência dessa cidade, encontram-se apenas centros de Zona A e B e Centros Locais da mesma forma que na região de influência de Guarapuava. No entanto, os dois Centros de Zona A são maiores em número de habitantes na área urbana que os que se localizam na área de influência de Guarapuava e, em função da dinâmica econômica de Ponta Grossa como um consolidado setor industrial, sua centralidade se estende a maior número de cidades e habitantes que Guarapuava. Segundo a SEFA-PR (2008), contribuiu com R $\$ 4.170 .084 .887$ do VAF/Total do município, nesse caso, equiparando-se ao VAF de Londrina o que esclarece sua distinção na rede urbana em relação à Guarapuava e reforça sua importância e dinâmica econômica no estado. 


\section{Figura 5: Região de Influência de Ponta Grossa - 2007}

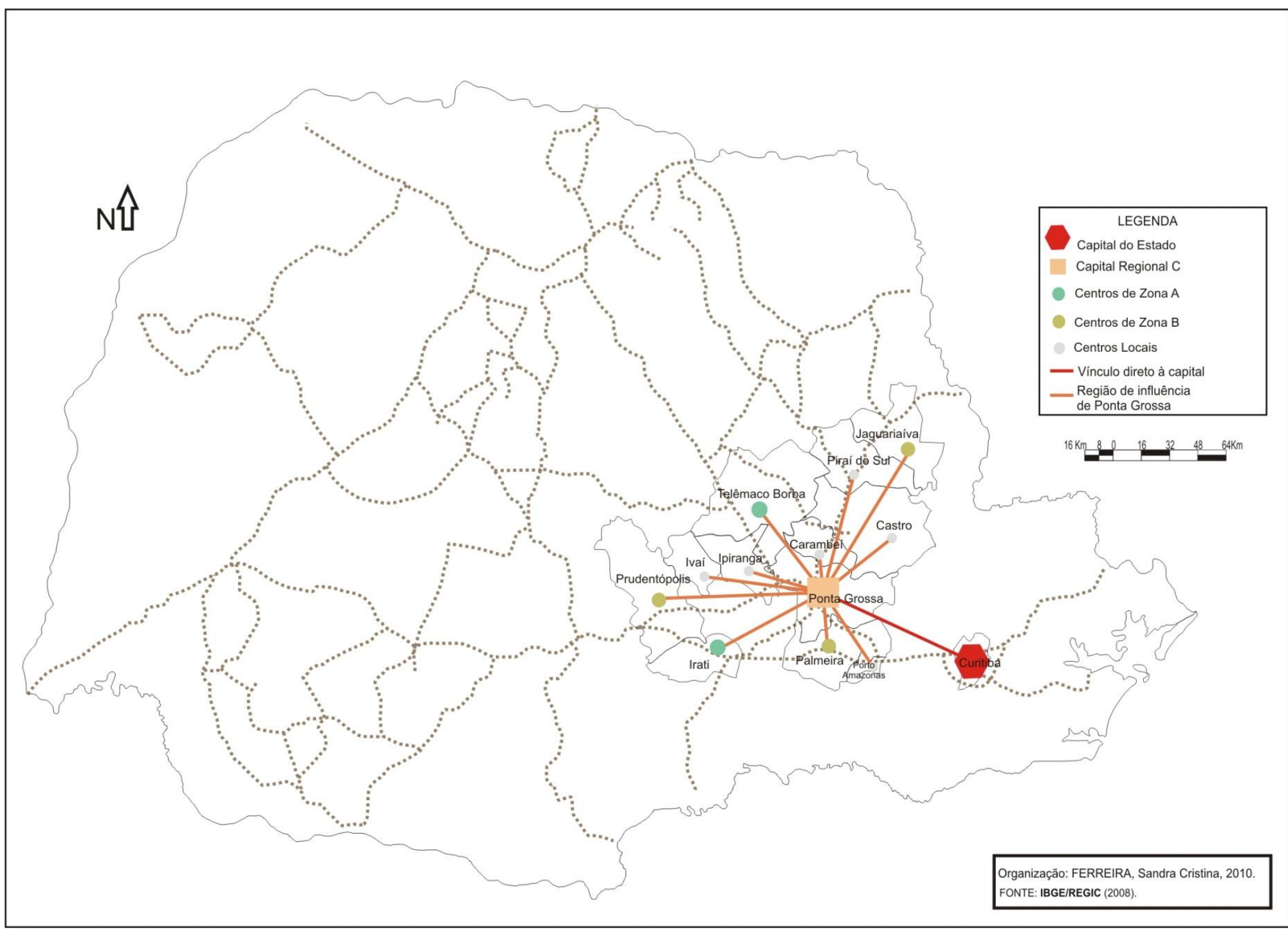




\subsection{Região de influência de Guarapuava}

As informações evidenciam a estabilidade ou estagnação apresentada por Guarapuava quanto ao nível de centralidade, com predominância a Centro Sub-regional na rede urbana do Paraná, diferenciando-se das maiores centralidades representadas por Londrina, Maringá, Cascavel e Ponta Grossa. Guarapuava ocupou a posição de Capital Regional apenas uma vez em 1978, quando se equiparou com Ponta Grossa e Cascavel.

Apresenta poucas modificações quanto a suas funções na hierarquia urbana paranaense, passando de Centro Sub-regional B, em 1966, à Capital Regional em 1978, depois à classificação segundo o nível de centralidade de Forte para Médio, em 1993, nível esse, equivalente ao Centro Sub-regional A, classificação recebida em 2007 (IBGE/REGIC, 2008).

Segundo a pesquisa de 2007, Guarapuava exerce influência direta sobre doze municípios distribuídos em sua região, além de Prudentópolis, localizado geograficamente na mesorregião Sudeste. Dos doze municípios, nove têm suas sedes como Centros Locais com uma média de 10 mil habitantes e três Centros de Zona B, sendo estes, Pitanga, Prudentópolis e Quedas do Iguaçu (Tabela 5).

\begin{tabular}{|c|c|c|}
\hline Cidades & Classificação & População Urbana \\
\hline Pitanga. & $\begin{array}{c}\text { Centro de Zona } \\
\text { B }\end{array}$ & 18.865 \\
\hline Prudentópolis. & $\begin{array}{c}\text { Centro de Zona } \\
\text { B }\end{array}$ & 21.661 \\
\hline Quedas do lguaçu. & $\begin{array}{c}\text { Centro de Zona } \\
\text { B }\end{array}$ & 19.973 \\
\hline $\begin{array}{l}\text { Campina do Simão, } \begin{array}{c}\text { Candói, } \\
\text { Cantagalo, } \\
\text { Goioxim, }\end{array} \text { Palmital, } \\
\text { Pinhão, Reserva do Iguaçu, Turvo. }\end{array}$ & Centros Locais & $\begin{array}{l}\text { Cidades com } 10 \text { mil } \\
\text { habitantes em média }\end{array}$ \\
\hline
\end{tabular}

Prudentópolis teve sua posição hierárquica na rede incrementada de Muito Fraco em 2000, equivalente a Centro Local (2007), para Centro de Zona B, em 2007, correspondente ao nível Fraco, em 2000. Esse Centro de Zona, com produção econômica vinculada à agricultura, relaciona-se, além de Guarapuava, com Ponta Grossa e Irati e polariza o Centro Local de Guamiranga. 
Pitanga reduziu sua posição na hierarquia de Médio para Fraco, em 2000, equivalente a Centro de Zona A, em 2007, para Centro de Zona B, em 2007 equivalente a posição Fraca em 2000. Sobressaem duas situações peculiares nesse contexto espacial, de um lado, Quedas do Iguaçu que localiza-se próxima à mesorregião de Cascavel, mas, segundo IBGE/REGIC(2008) pertence à área de influência de Guarapuava como Centro de Zona B. Por outro, Laranjeiras do Sul, embora se localize na mesorregião Centro Sul paranaense e apresente-se como uma das cidades mais bem posicionadas quanto à hierarquia urbana, não está sob a área de influência direta de Guarapuava, mas na de Cascavel.

Laranjeiras do Sul, perdeu centralidade passando de nível Médio (2000) equivalente a Centro sub-regional B (2007), para Centro de Zona A (2007), equivalente ao nível Médio para Fraco, em 2000, enfraquecendo a influência sobre as cidades de sua hinterlândia. Tal realidade socioespacial, encontra-se em perspectiva de superação devido à implantação em 2009, da Universidade Federal da Fronteira Sul na referida cidade, o que tem proporcionado impulso à dinâmica socioeconômica do município e intensificado a produção do espaço urbano segundo pesquisas realizadas por Ferreira (2011).

Entre as cidades que se encontram sob a área de influência de Guarapuava, nenhuma possui número populacional maior que 50 mil, pelo contrário, o maior número de habitantes na área urbana concentra-se em Prudentópolis com 21.661 (IBGE, 2007), como evidencia a Figura 6. O fator demográfico, associado à quantidade de cidades com inexpressiva dinâmica econômica resultante do modelo produtivo com pouca capitalização, a referida região de influência configura uma dinâmica menos expressiva que a representada por Londrina, Maringá, Cascavel e Ponta Grossa, como cidades que estabelecem maior quantidade e intensidade de fluxos e interações espaciais na rede urbana do estado como antecipamos nessa discussão.

Salientamos que a inexpressividade de papéis na rede urbana não se atribui somente à dinâmica demográfica, mas, principalmente às condições socioeconômicas que resulta na restrição das atividades de produção e consumo podendo ser comparado em relação às demais cidades pelo VAF/T (Valor Adicionado Fiscal Total). Guarapuava em 2008 segundo a SEFA/PR (Secretaria de Estado e Fazenda do Paraná) o VAF/Total foi de $R \$$ 1.528.972.999, quase a metade do valor de Cascavel que foi $\mathrm{R} \$ 2.849 .669 .946$. Guarapuava teve o menor VAF frente aos valores apresentados por Londrina, Maringá e Ponta Grossa. 


\section{Figura 6: Região de Influência de Guarapuava - 2007}

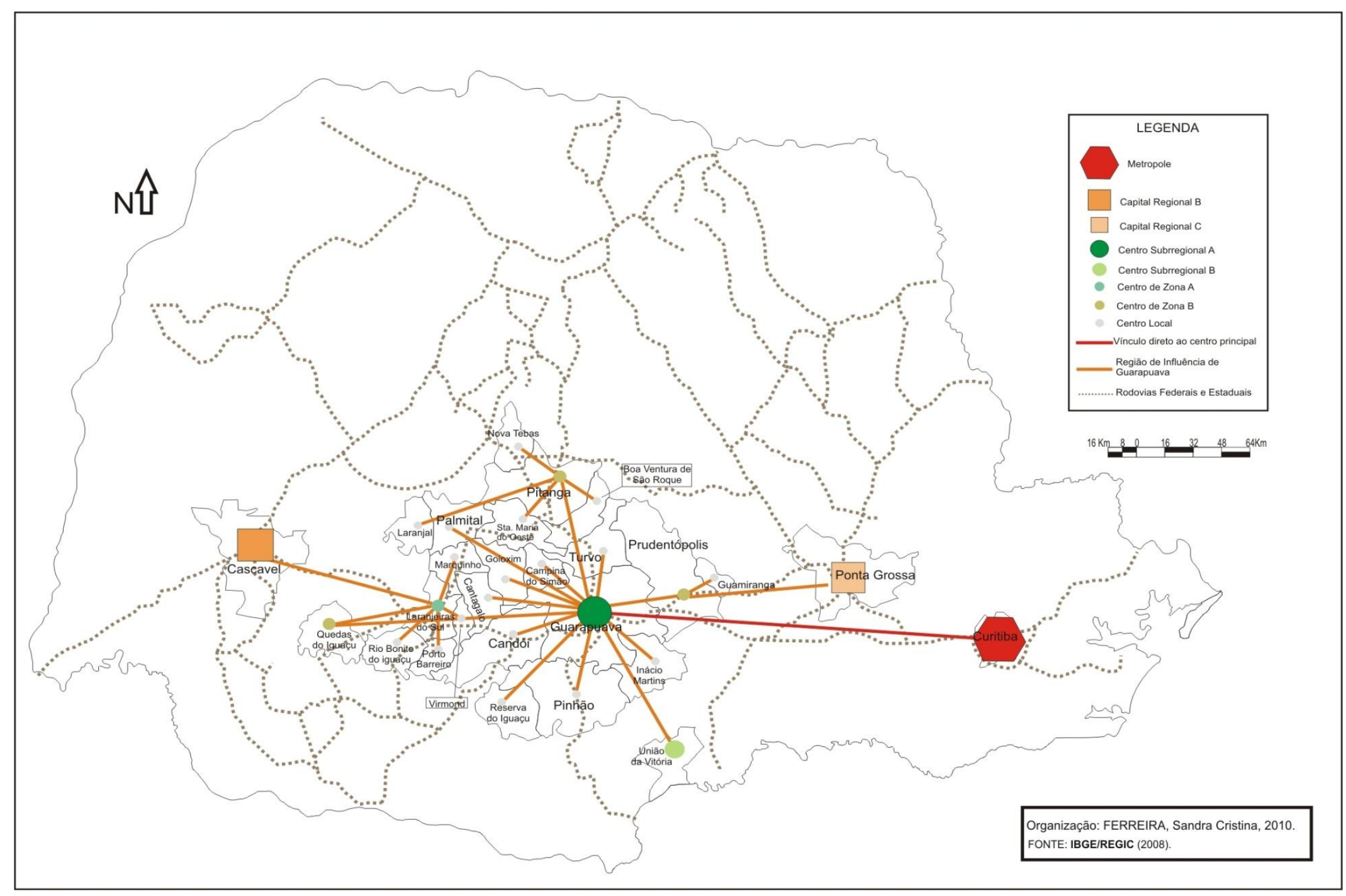




\section{Considerações Finais}

Corroboramos com CORRÊA (2004, 2006), a afirmação de que a rede urbana é uma construção social, mas, acrescentamos que essa construção é regida por uma ordem política além da econômica e o estudo da formação, desenvolvimento e consolidação da rede urbana paranaense nos reforça esse entendimento.

$\mathrm{Na}$ caracterização da rede urbana paranaense em 2007, levando-se em consideração os parâmetros demográficos e econômicos, torna-se evidente a primazia e o alcance da influência de Curitiba sobre as demais cidades do estado evidenciando também, a concentração da oferta de bens e serviços, dos equipamentos urbanos de consumo coletivo, tanto públicos quanto privados, além das funções políticas e administrativas que força ao deslocamento de pessoas de diferentes cidades e distâncias em direção à capital.

Lembramos que, a população de Curitiba somada a de sua Região Metropolitana constitui um elevado contingente, sobretudo, de pessoas pertencentes às demandas sociais carentes de serviços públicos. As cidades de maior hierarquia destacadas nesse artigo, quais sejam: Londrina, Maringá, Cascavel, Ponta Grossa e Guarapuava, também apresentam elevada concentração populacional na área urbana e constituem polos para atendimento de habitantes de suas regiões.

Diante do exposto no decorrer do texto, em relação a quantidade de habitantes na áreas urbana das regiões de influência de cada urbe destacada, consideramos que a quantidade de cidades "pólos de desenvolvimento" ou "localidades centrais" segundo as referências teóricas e metodológicas que fundamentaram os estudos do IBGE/REGIC e antes disso, fundamentaram os Planos Nacionais de Desenvolvimento (PNDs), são insuficientes para a atual realidade socioeconômica paranaense.

A política de centralização de bens e serviços em desequilíbrio entre a oferta e a procura ao mesmo tempo em que amplia a possibilidade de obtenção de lucro por parte do comercio e das prestações de serviços nessas localidades, por um lado, acarreta em problemas sociais e ambientais para a capital e demais cidades de maior centralidade na rede urbana paranaense pela dificuldade de atendimento a contento de toda a população atraída. Por outro lado, para a grande quantidade de cidades de menor hierarquia na rede urbana, desprovidas de equipamentos urbanos de consumo coletivo, principalmente, aqueles referentes à saúde e educação, assim como, de condições de produção e de 
oferta de bens e serviços diversos, apresentam dificuldades para a consolidação na rede urbana como cidades com potencial para o atendimento de sua população e isso, ao nosso ver, deveria acontecer independente do tamanho populacional.

No centro dessa relação de produção e consumo orientada por políticas de distribuição de recursos federais e estaduais para investimentos nas cidades, a população de modo geral, sejam aquelas residentes em urbes de maior ou menor hierarquia urbana é que vivencia as dificuldades procedentes desse modelo de desenvolvimento, ainda centralizado, que prioriza parcelas do espaço e o capital em detrimento da população. Consideramos que as interações espaciais deveriam acontecer mais por desejos que por necessidades de deslocar-se e, que a cidade pequena deveria oferecer atendimento qualitativo à maior parte das necessidades da população residente e de sua área de influência imediata.

Do ponto de vista da estruturação da rede urbana destacam-se segundo a conformação atual da rede, as cidades de Londrina, Maringá, Cascavel e Ponta Grossa que dinamizam o contexto regional e contribuem para um relativo equilíbrio na intensidade dos fluxos que caracterizam a rede urbana, diminuindo vetores ou a intensidade dos fluxos de pessoas rumo à Curitiba. Exceto por estas áreas mais dinamizadas, a rede urbana paranaense prossegue com áreas caracterizadas por dinâmica socioeconômica menos intensa, assentadas em municípios menos pujantes e distantes de áreas de influência das principais cidades. Estes núcleos urbanos e seguem fortemente dependentes de Curitiba, conduzindo a população dessas áreas a deslocamentos freqüentes para o atendimento de suas necessidades, como o que acontece com habitantes do Centro do estado.

Guarapuava por exemplo, figura como um dos municípios de porte médio com mais de 100 mil habitantes e menor expressividade na rede urbana, integrando-se a Curitiba e Ponta Grossa enquanto cidades de hierarquia superior no suprimento das demandas por bens e serviços não contempladas em seu mercado.

Essa diferença de papel na rede, em parte se explica pelo histórico da formação socioespacial de Guarapuava vinculada por um longo período à exploração vegetal, criação de gado e agricultura tradicional. Também pelas as características culturais e as condições gerais de produção existentes em sua sociedade e espaço que proporcionou o adentrar mais lento ao modelo de desenvolvimento nacional pautado na modernização da agricultura, industrialização e urbanização. 
Frente ao cenário de desenvolvimento territorial promovido no Brasil, no decorrer do tempo, Londrina, Maringá, Cascavel e Ponta Grossa até mesmo por terem sido valorizadas nas políticas ${ }^{2}$ estaduais de desenvolvimento urbano, alcançaram condições socioeconômicas que tornaram possível a elevação destas cidades na rede urbana como centros mais representativos do ponto de vista da produção, disponibilidade de bens e serviços e interações espaciais por meio dos fluxos gerados, sendo estes, de maior alcance e intensidade que os gerados entre Guarapuava e sua hinterlândia.

Assim, cidades com população entre 50 e 100 mil e entre 100 e 500 mil habitantes, somadas aos às cidades pequenas e aos centros locais, configuraram no estado espaços com maior quantidade de urbes tornando-os mais densos quanto as interações espaciais como as áreas que se formam a partir das interações entre Londrina, Maringá e seu entorno, Cascavel que intermedia relações de fronteira e estende sua influência sobre uma área que abrange além das pequenas cidades em seu entorno, urbes como Foz do Iguaçu, Toledo e, Ponta Grossa que articulada a Curitiba e seu entorno apresenta maior densidade de fluxos entre os núcleos urbanos.

As características observadas na rede urbana do Paraná, reforça que o padrão de rede menos equilibrado quanto à distribuição, tamanho e funções das cidades condiz tanto com a formação territorial segmentada no tempo e no espaço, cujo componente social deriva de diferentes segmentos socioculturais quanto pelas ações do Estado em escala federal, estadual e municipal.

O setor privado por sua vez, vinculado ao empreendedorismo local/regional também representa significativo agente na atribuição de especificidades, diferenciando as cidades na rede urbana. Portanto, a formação socioespacial considerando inerentes à essa categoria os processos desencadeados pelos agentes sociais, políticos e econômicos, sendo estes dois últimos traduzidos especificamente na presença do Estado e do Capital público e privado, constitui importante categoria analítica para os estudos da rede urbana, sobretudo, quando a investigação parte da escala regional (FERREIRA, 2011). Nesse sentido, compreendemos que além dos aspectos históricos e geográficos pertinentes à sociedade e ao espaço paranaense, a formação, desenvolvimento e atual configuração da rede urbana do Paraná está relacionada à processos político-econômicos oriundos de escalas mais amplas e que, diferentemente repercutem sobre a população e as cidades que constituem a rede urbana.

\footnotetext{
${ }^{2}$ Sorte que não recaiu sobre Guarapuava embora eleita para investimentos em cidades de porte médio pelo governo federal, fato que merece outra discussão em momento oportuno.
} 


\section{Referências Bibliográficas}

CORRÊA, R. L. Rede urbana: reflexões, hipóteses e questionamentos sobre um tema negligenciado. In: Cidades: Revista científica/Grupo de Estudos Urbanos. Vol. 1, n. 1, 2004 - v. 1.

Estudos sobre a rede urbana. Rio de Janeiro. Bertrand do Brasil, 2006.

FERREIRA, S. C. A formação socioespacial como orientação teórico-metodológica no estudo da rede urbana regional. In: Caminhos de Geografia, Uberlândia v. 12, n. 37 mar/2011 p. $1-7$ Página, Belo Horizonte, 2011. Disponível em http://www.ig.ufu.br/revista/caminhos.html. Acessado em junho de 2011.

FERREIRA, S. C. Rede urbana, cidade de porte médio e cidade média: estudos sobre Guarapuava no estado do Paraná. (Tese Doutorado). Universidade Estadual Paulista/UNESP: Campus de Presidente Prudente, São Paulo, 2010.

FERREIRA, S. C. PRADA, J. S. A centralidade da pequena cidade na rede urbana regional: estudos sobre a oferta de bens e serviços em Laranjeiras do Sul-PR. Projeto de Iniciação Científica. UNICENTRO, Guarapuava, 2011.

IBGE. INSTITUTO BRASILEIRO DE GEOGRAFIA E ESTATÍSTICA. Contagem da população. 2007. http:/www.sidra.ibge.gov.br. Acessado em abril de 2010.

IBGE. INSTITUTO BRASILEIRO DE GEOGRAFIA E ESTATÍSTICA. Estimativa da população. 2009. http:/www.sidra.ibge.gov.br. Acessado em abril de 2010.

IBGE. Regiões de Influência de Cidades - 2007. Rio de Janeiro. IBGE, 2008.

IPARDES. Os vários Paranás: estudos socioeconômico-institucionais como subsídio aos planos de desenvolvimento regional. Curitiba, 2005.

IPARDES. Os vários Paranás: identificação de espacialidades socioeconômicoinstitucionais como subsídio a políticas de desenvolvimento regional. Curitiba, 2006.

IPARDES. Os Vários Paranás. Oeste paranaense: especificidades e diversidades. Curitiba, 2008.

IPARDES. Instituto Paranaense de Desenvolvimento Econômico e Social. Comentários sobre os resultados do REGIC/2007. Instituto Paranaense de Desenvolvimento Econômico e Social. Curitiba, 2009.

MOURA, Rosa. Paraná: meio século de urbanização. R. RA`E GA, Curitiba, n. 8, p. 33-44, 2004.

REOLON, C. A. A aglomeração urbana da soja: Cascavel e Toledo no contexto da metropolização na Mesorregião Oeste Paranaense. 2007. Dissertação (Mestrado) UNIOESTE/Campus de Toledo, Toledo, 2007. 